\title{
A RESEARCH ON MONITORING SURFACE DEFORMATION AND RELATIONSHIPS WITH SURFACE PARAMETERS IN QINGHAI TIBETAN PLATEAU PERMAFROST
}

\author{
S.J. Mi ${ }^{\text {a.b.*, Y.T. } \mathrm{Li}^{\text {a }} \text {, F.Wang }}{ }^{\text {a }}$ L. Li ${ }^{\text {a }}$, Y. Ge ${ }^{\text {a }}$, L. Luo ${ }^{\text {a }, ~ C .1 . ~ Z h a n g ~}{ }^{\text {a }}$ J.b. Chen ${ }^{\text {c }}$ \\ ${ }^{a}$ China Transport Telecommunications \& Information Center, 100011, Beijing, China, (misujuan, liyuanting,wangfang, lili01, geyin, \\ luoluo, zhangchunlei)@ cttic.cn \\ ${ }^{\mathrm{b}}$ State Key Laboratory of Frozen Soil Engineering, Northwest Institute of Eco-Environment and Resources, Chinese Academy of \\ Sciences, Lanzhou 730000, Gansu, China \\ ${ }^{\mathrm{c}}$ CCCC First Highway Consultants CO.,LTD, Xi’an 710075,Shaanxi, China, chenjb@ccroad.com.cn
}

Commission III, WG III/3

KEY WORDS: Deformation, Sentinel, Soil Moisture, Permafrost, Qinghai Tibetan Plateau

\begin{abstract}
:
The Qinghai Tibetan Plateau permafrost has been the largest permafrost region in middle-low latitude in the world for its high altitude. For the large area permafrost, especially surface deformation brought by it, have serious influence on the road engineering, road maintaining and regional economic development. Consequently, it is essential to monitor the surface deformation and study factors that influent it. We monitored an area named Wudaoliang from July 25, 2015 to June 1, 2016 and 15 Sentinel images were obtained during this time. The area we chose is about 35 kilometers long and 2 kilometers wide, and the national road 109 of China passes through the area. The traditional PS-INSAR (Persistent Scatterer Interferometric Synthetic Aperture Radar) method is not suitable because less historical images in the research area and leading to the number of PS (Persistent Scatterer) points is not enough to obtain accurate deformation results. Therefore, in this paper, we used another method which named QUASI-PSInSAR (QUASI Persistent Scatterer Interferometric Synthetic Aperture Radar) to acquire deformation for it has the advantage to weaken or eliminate the effects of spatial and temporal correlation, which has proved by other scholar. After processing 15 images in the SARproz software, we got the conclusions that, 1) the biggest deformation velocity in the whole area was about $127.9 \mathrm{~mm} / \mathrm{year}$ and about $109.3 \mathrm{~mm} /$ year in the road; 2) apparent deformation which have surface deformation more than $30 \mathrm{~mm} /$ year was about $1.7 \mathrm{Km}$ in the road. Meanwhile, soil moisture(SM), Land surface temperature (LST) and surface water(SW), which are primary parameters of the land surface over the same time were reversed by using Sentinel data, Landsat data and ZY-3 data, respectively. After analyzing SM, LST, SW and deformation, we obtained that wet areas which had bigger SM, lower LST and more SW, had greater percentage of severe deformation than arid areas; besides, deformation pattern were different in arid areas and wet areas. During the research time, frost heaving firstly accounted for a large proportion both in the arid and wet areas with the decrease of downward radiation from July to December; after December, thaw settlement came into prominence with the increase downward radiation in the arid areas, while in the wet areas, surface put into diverse situations because of water transformation leading to severe deformation. In summary, soil moisture is an important factor that influences the surface deformation. This relationship between deformation process and soil moisture will be researched more in our further work.
\end{abstract}

\section{INTRODUCTION}

Permafrost is one of the most important factors in land surface process of cold regions. It is extremely sensitive to global warming and seriously affects the ground ecological, hydrological, geophysical and biogeochemical processes in cold areas (Nelson, 2001; Short, 2011). In cold area, surface deformation is a main factor to influence the transport infrastructure construction and also has a great impact on the stability of the road and its daily maintenance (Zhao, 2016). The land surface temperature is an important factor on surface freezing and thawing; at the same time, soil moisture changes with surface freezing and thawing. Therefore, it is essential to research the relationship between surface deformation and other surface parameters.

With the development of remote sensing, especially the SAR and high spatial resolution technology, it is possible to research surface deformation and relationships in a big region. Therefore, this paper attempted to estimate land surface parameters by using remote sensing images in Qinghai Tibetan Plateau
Permafrost. The data and processing method were introduced in Section 2; the analysis and conclusion were shown in Section 3 and Section 4, respectively.

\section{DATA AND PROCESSING}

\subsection{Data}

In this paper, we proposed a method which using the Sentinel-1 data to extract the deformation information of the Qinghai-Tibet Highway, and using the high resolution remote sensing data to extract the surface temperature, soil moisture and water of the road area to analyse the relationship among these parameters . The SENTINEL-1 A | B satellite is an Earth observation satellite developed by ESA and AIRBUS in the European Space Agency's Copernicus Plan (GMES), consisting of two satellites using C-band synthetic aperture radar. SENTINEL satellites have high accuracy of track control and ground positioning, and their image products are widely used in settlement monitoring, which can provide high quality monitoring image data sets for medium and low scale ground subsidence monitoring services

\footnotetext{
* Corresponding author
} 
(Paloscia, 2013; Venera,2016).In this paper, the Landsat ETM + data and the Landsat TM8 data were used to estimating 8 temporal surface temperature (Rodriguez-Galiano,2012). The $15 \mathrm{~m}$ Landsat TM 8 satellite data source was supplemented from November of 2015 to June of 2016 to select a monthly coverage remote sensing data for extracting water.The remote sensing data used for retrieving soil moisture was from the radar satellite Sentinel-1A IW distance image with a resolution of 20 * 40 meters and a polarization mode of VV. 9 images covering the study area were obtained from 1 July 2015 to 25 May 2016, about one image per month for analysis of permafrost soil moisture in different seasons easily. The data sets of the data used in this paper were shown bellowing.

\begin{tabular}{|c|c|c|}
\hline $\begin{array}{c}\text { Land } \\
\text { Parameter } \\
\mathrm{s}\end{array}$ & Numbers & Times \\
\hline $\begin{array}{c}\text { Surface } \\
\text { deformati } \\
\text { on }\end{array}$ & 15 & $\begin{array}{c}\text { Aug.18th,Sep.11th,Oct.5th,Oc } \\
\text { t.29th,Nov.22th,Dem.16th,Jan } \\
\text { 9th,Feb.2th,Feb.26th,Mar.21, } \\
\text { Apr.14th,May } \\
\text { 8th,Jun.1th,Jul.19th }\end{array}$ \\
\hline $\begin{array}{c}\text { Soil } \\
\text { Moisture }\end{array}$ & 10 & $\begin{array}{c}\text { Jul.1th,Aug.6th,Sep.11th,Oct. } \\
\text { Nov.15th,Jan.2th,Feb.2th,Api. } \\
\text { 14th, May 8th,May 25th }\end{array}$ \\
\hline LST & 8 & $\begin{array}{c}\text { Oct.11th,Oct.27th, Dec.30th, } \\
\text { Jan.23th,Feb.17th, Mar.11th, } \\
\text { Api.12th, Jun.7th }\end{array}$ \\
\hline $\begin{array}{c}\text { Surface } \\
\text { Water }\end{array}$ & 7 & 2015.12-2016.06 \\
\hline
\end{tabular}

Table 1. The information of the data used in this paper

\subsection{Processing}

\subsubsection{INSAR}

After processing 15 InSAR images in the Wudaoliang by the SARProZ software, the following parameters could be obtained:

(1) The time interval of the re-visit is 24 days and the longest interval is 48 days (1), which can fully guarantee the time correlation of the data set;

(2) The space baseline of data set is less than 150 meters. The short space baseline can facilitate the accurate registration of data and ensure good data coherence to eliminate errors and atmosphere effect;

(3)Maximum Doppler center frequency offset is less than $0.06 \mathrm{~Hz} / \mathrm{PRF}$

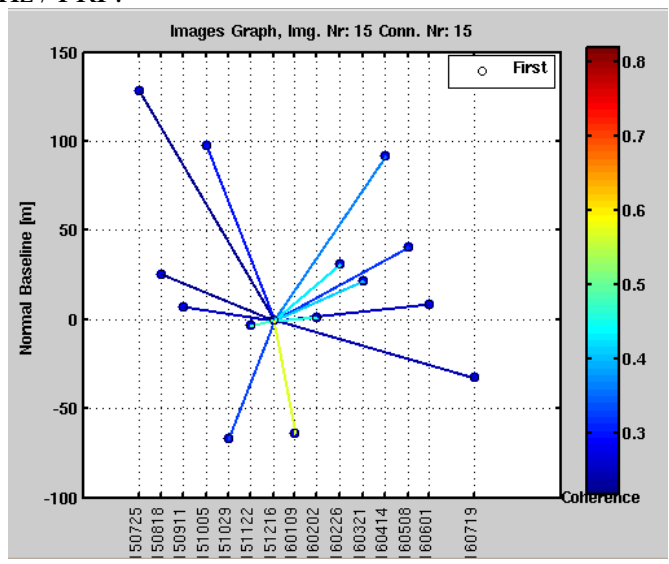

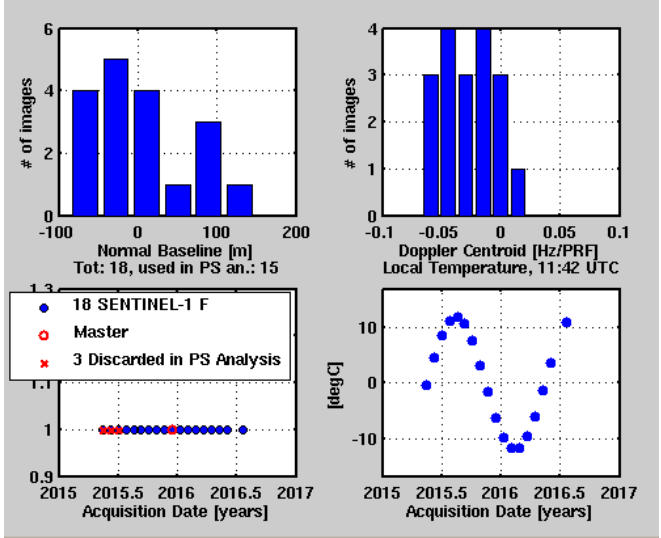

Figure 1 Statistical information of the data set

QUASI-PSInSAR approach includes subset celection, coregistration, preliminary analysis, correction of APS and sparse points processing.

\subsubsection{Soil moisture}

Radar backscattering coefficient can be expressed as Eq. (1) for bare soil surface with $\mathrm{HH}$ or VV polarisation (Woodhouse and Hoekman, 2000; Wen, 2003). Eq. (1) can be applied to retrieve soil moisture over the experimental sites, and the contributions of vegetation backscattering coefficients can be neglected in this research.

$$
\sigma_{\text {soil }}^{0}(\theta)=\frac{|\Gamma(0)|^{2} \exp \left(-\frac{\tan ^{2} \theta}{2 s^{2}}\right)}{2 s^{2} \cos ^{4} \theta}
$$

Where $\mathrm{s}$ is the root mean square (RMS) slope of surface height, $\Gamma(0)$ is soil Fresnel reflectivity at normal incidence of a halfspace with a relative permittivity. For differenet soil texture, a linear or quasi-linear relationship exists between Fresnel reflectivity and soil moisture with different empirical constants in different frequency band.

The above available algorithm was used to retrive soil moisture with Sentinel-1A IW GRDH data in VV polarization from July 2015 to May 2016, the results are shown in Figure 2.

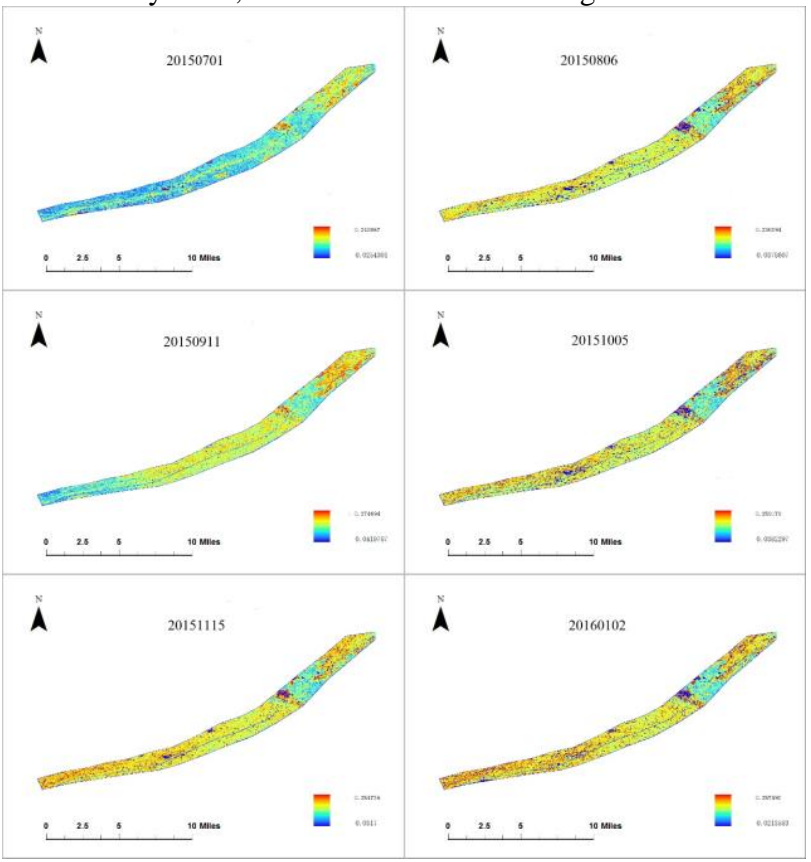




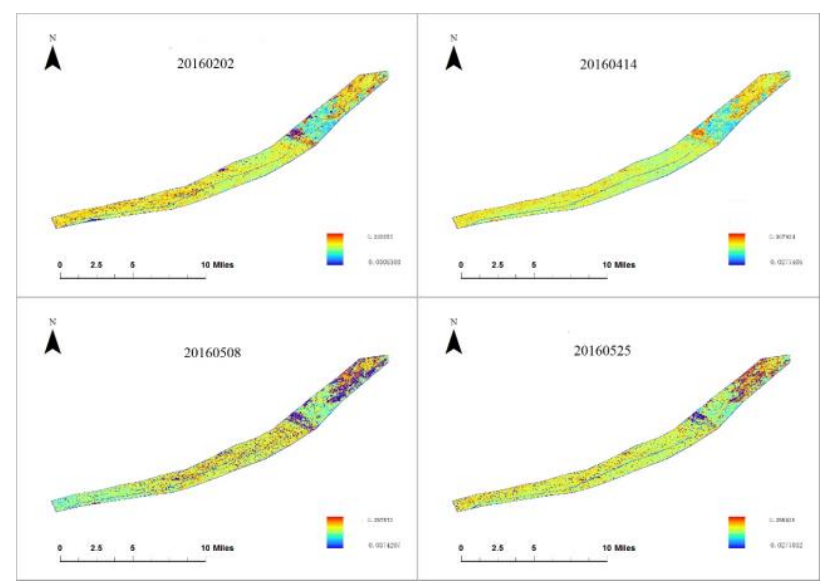

Figure 2. Soil moisture distributions derived from Sentinel-1A over the study area

\subsubsection{Land surface temperature}

From the introduction of data at the ahead, it can be known that two kinds of images were used to retrieving land surface temperature. The theory and method are quite different on retrieving LST using ETM+ and TM8 for different numbers of thermal infrared bands. The flow charts of retrieving LST by two images are shown below.

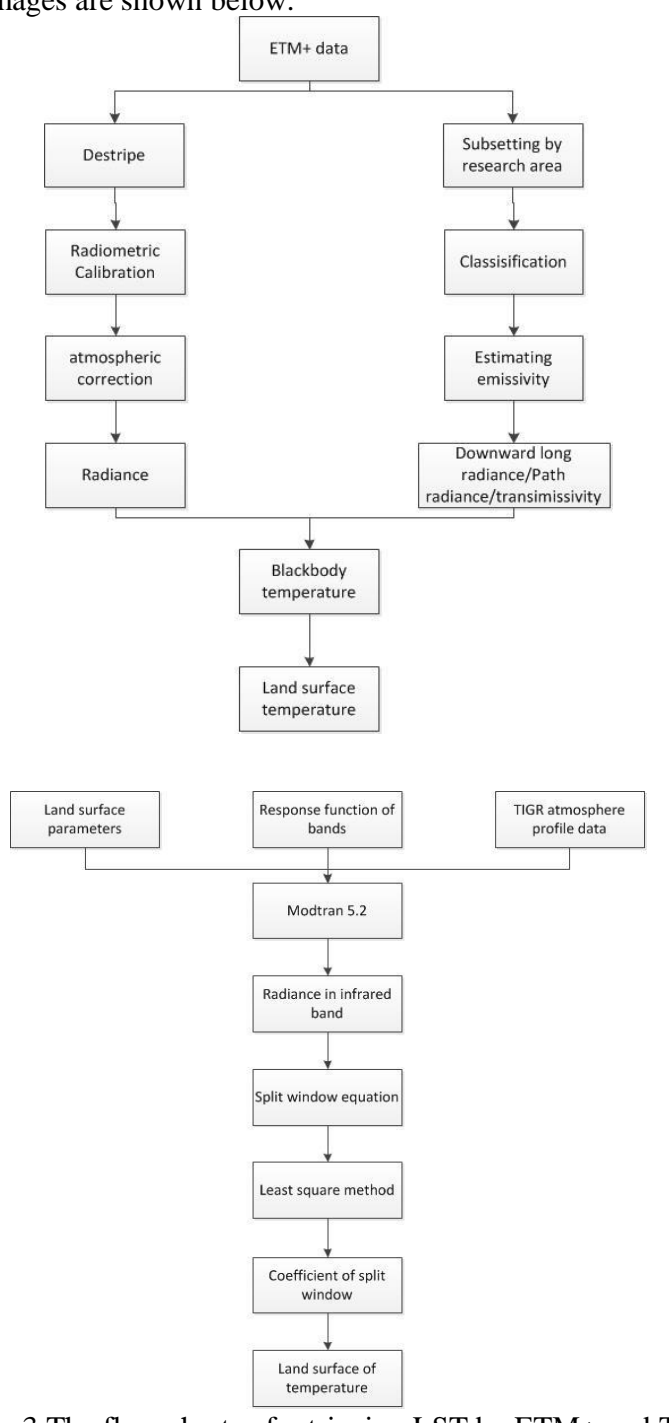

Figure 3 The flow charts of retrieving LST by ETM+ and TM 8
After we obtained the radiance of blackbody in thermal infrared band, we estimated actual land surface temperatures Ts by Plank black-body radiation formula, which was shown in eq.(2).

$$
T_{S}=\frac{K_{2}}{\ln \left(\frac{K_{1}}{B\left(T_{S}\right)}+1\right)}
$$

Where, $K_{1}$ is about 66.09 (W/M2.sr.um) and $K_{2}$ is about $282.71 \mathrm{~K}$ in the ETM+ data.

The formula to estimation LST in TM 8 was shown in eq. (3) (Wan, 1996).

$$
\begin{aligned}
& T_{s}=b_{0}+\left(b_{1}+b_{2} \frac{1-s}{s}+b_{3} \frac{\Delta s}{s}\right) \frac{T_{i}+T_{j}}{2}+ \\
& \left(b_{4}+b_{5} \frac{1-\varepsilon}{s}+b_{6} \frac{\Delta s}{s}\right) \frac{T_{i}-T_{j}}{2}+b_{7}\left(T_{i}-T_{j}\right)^{2}
\end{aligned}
$$

Where $\varepsilon$ and $\Delta \varepsilon$ are the average and difference emissivity values of two bands, which depend on the land cover types; $T_{i}$ and $T_{j}$ are the radiance of two bands; bi are the coefficients of each part, which depend on the water vapor content and can be obtained by laboratory experiments 、 atmospheric parameter or Atmospheric radiation transfer equation. The LST results of 8 times were shown below.
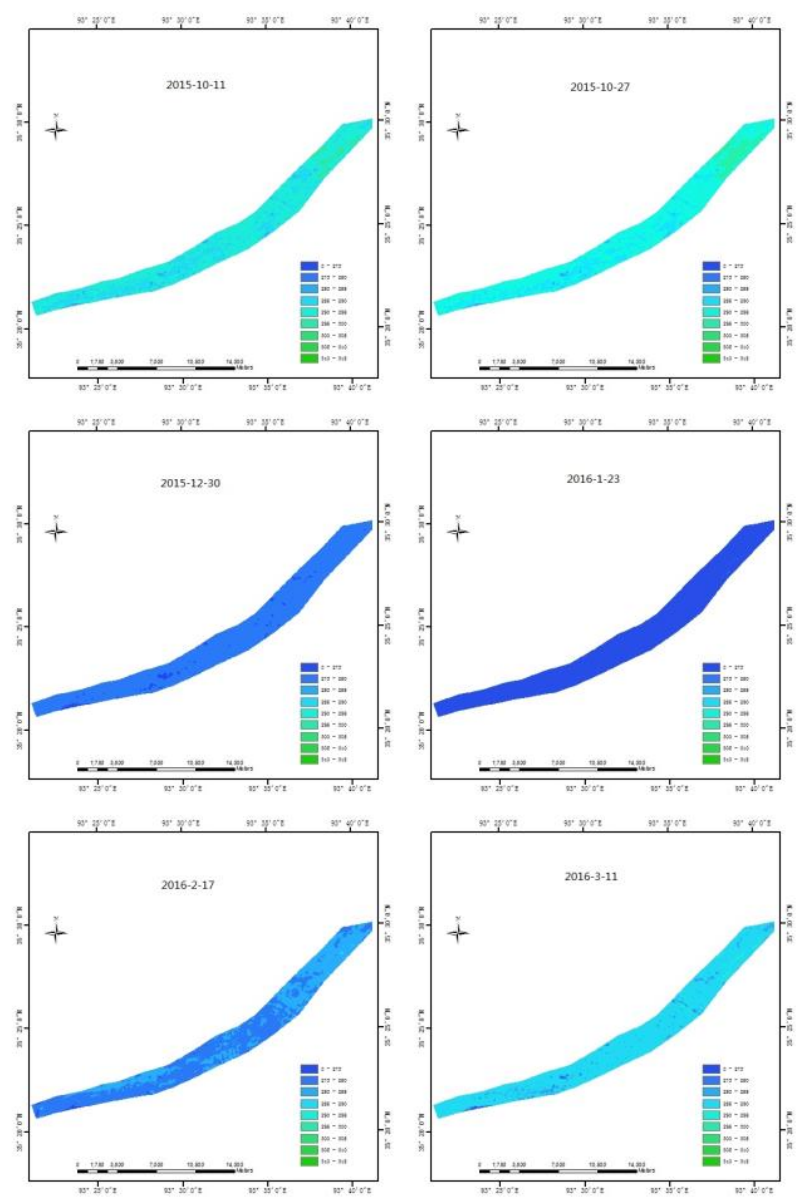

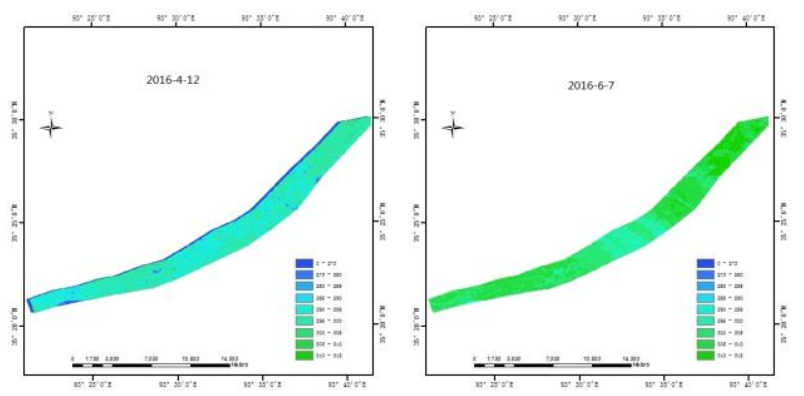

Figure 4. LST distributions derived from Landsat ETM+ and TM 8 over the study area

\section{ANALYZING}

\subsection{Surface deformation analysis}

After processing the data set, it was found that the main settlement centers in this area were distributed in three areas shown in the following figure during the observation period from July 1, 2015 to July 19, 2016. The settlement contour map was generated by interpolating the PS points to form a fixed sampling interval which can clearly show the position and influence range of the settlement center. The time series settlement variation of ground permanent scatter points can be extracted by the QPS technique. The settlement variation of the permanent scattering points on the National road 109 was basically consistent with the trend in the frozen soil area.

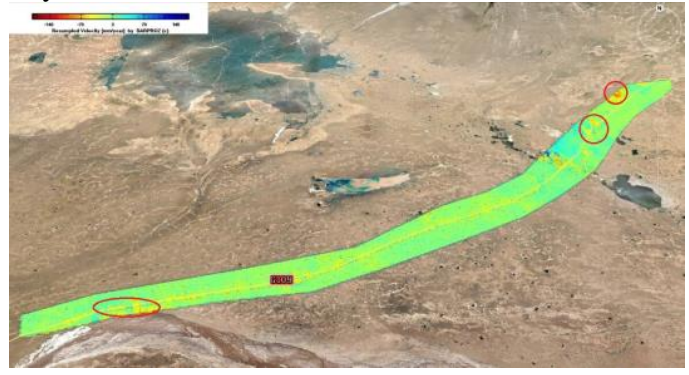

Figure 5 The distribution of settlement PS points

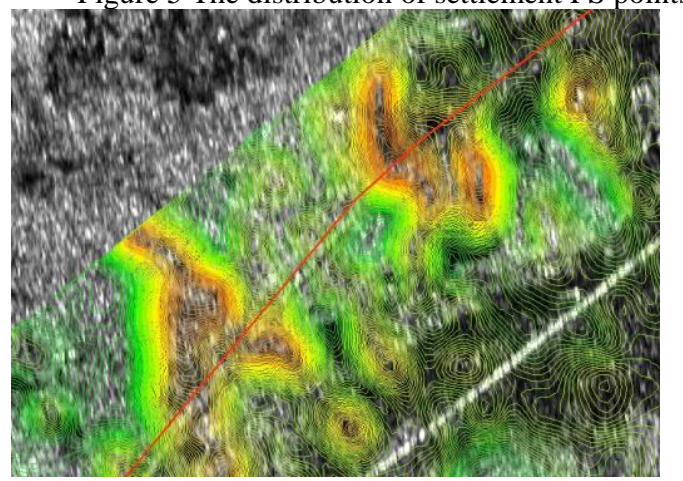

Figure 6 Ground subsidence contour map and highway overlay effect (enlarged view)

\subsection{The relationship among these parameters}

From August 2015 to June 2016, the Cumulative probability distribution of surface deformation, surface temperature, surface soil moisture and water for arid and humid area were shown in Figure 7-10. The Maximum distribution probability of surface deformation in arid and humid area for all dates were shown in Figure 11.

\section{CONCLUSION}

In this paper, we first obatined surface deformation, soil parameter, soil temperature and surface water from July, 2015 to July 2016 by Sentinel-1, Landsat ETM+, Landsat TM8 and ZY-3 data. Then the relationship among these parameters were analysed by probability statistical approach.

From this paper, we can get that the surface deformation of Qinghai Tibetan Plateau Permafrost can be estimated by Sentinel-1 data and the accuracy can research millimetres, which is not only helpful to research the influences to roadbed in different seasons ,but also provides information to the road maintenance.

After analysing the relationship among surface deformation, soil moisture, soil temperature and surface water, it can be get that surface moisture is in proportion to surface deformation and areas where have bigger soil moisture are more likely to occur server deformations in frozen regions.

\section{ACKNOWLEDGEMENTS}

This work was Supported in part by The National Key Research and Development Program of China 2017YFB0503803.

\section{REFERENCES}

[1]Nelson,F.E.,Anisimov,O.A.Shiklomanov,N.I.,2001.subsiden ce risk from thawing permafrost, Nature 410(6831),889-890;

[2]Short,N.,Brisco,B.Couture,N.,Pollard,W.,Murnaghan,K.,Bud kewitsch,P.,2011.A comparison of TerraSAR-X, RADARSATand ALOS-PALSAR interferometry for monitoring permafrost environments, case study from Herschel Island, Canada,Remote Sensing of Environment,115(2),pp,3491-3506.

[3] Zhao R, Li Z W, Feng G C, et al. 2016.Monitoring surface deformation over permafrost with an improved SBAS-InSAR algorithm: With emphasis on climatic factors modeling. Remote Sensing of Environment, 184,pp,276-287.

[4]Paloscia S, Pettinato S, Santi E, et al. 2013. Soil moisture mapping using Sentinel-1 images: Algorithm and preliminary validation. Remote Sensing of Environment, 134(4),pp,234-248.

[5] Venera J, Anton F, Irina K, et al. 2016. SAR Interferometry Technique for Ground Deformation Assessment On Karazhanbas Oilfield. Procedia Computer Science, 100, pp, 1163-1167.

[6] Rodriguez-Galiano V, Pardo-Iguzquiza E, Sanchez-Castillo M, et al. 2012. Downscaling Landsat 7 ETM+ thermal imagery using land surface temperature and NDVI images. International Journal of Applied Earth Observation \& Geoinformation, 18(1), pp, 515-527.

[7]Woodhouse, I.H., Hoekman, D.H. 2000. Determining landsurface parameters from the ERS Wind scatterometer. IEEE Trans. Geosci. Remote Sens.38 (1), pp, 126-140,.

[8] J Wen, Z Su, 2003, The estimation of soil moisture from ERS wind scatterometer data over the Tibetan plateau, Physics \& Chemistry of the Earth, 28 (1), pp, 53-61

[9] Wan Z, Dozier J. 1996. A generalized split-window algorithm for retrieving land-surface temperature from space. IEEE Transactions on Geoscience \& Remote Sensing, 34(4), pp, 892-905. 


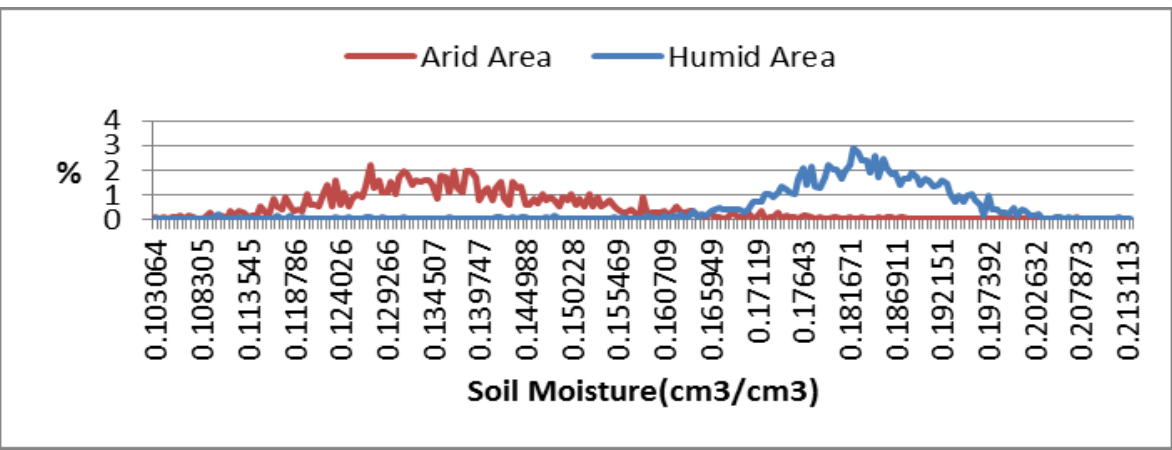

Figure 7 The Cumulative probability distribution of volume soil moisture in arid and humid areas

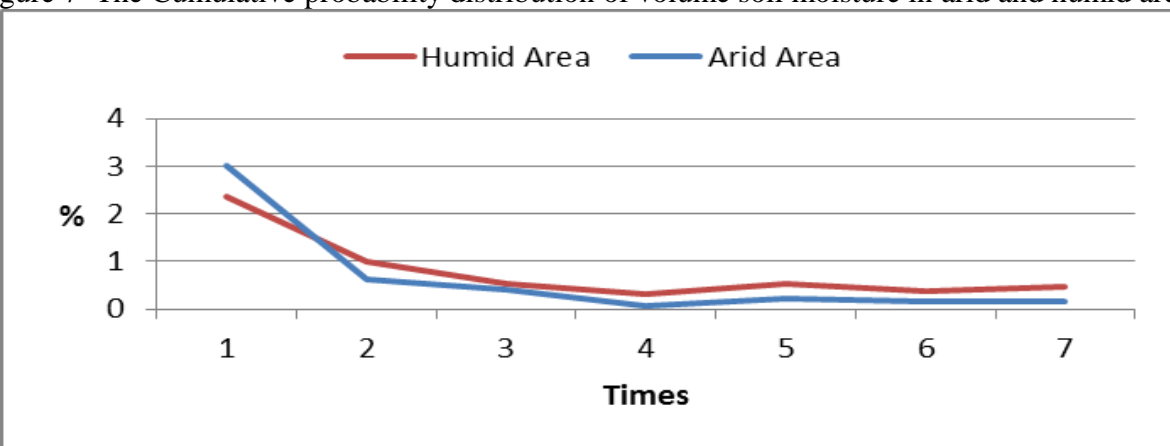

Figure 8 The Cumulative probability distribution of water in arid and humid areas

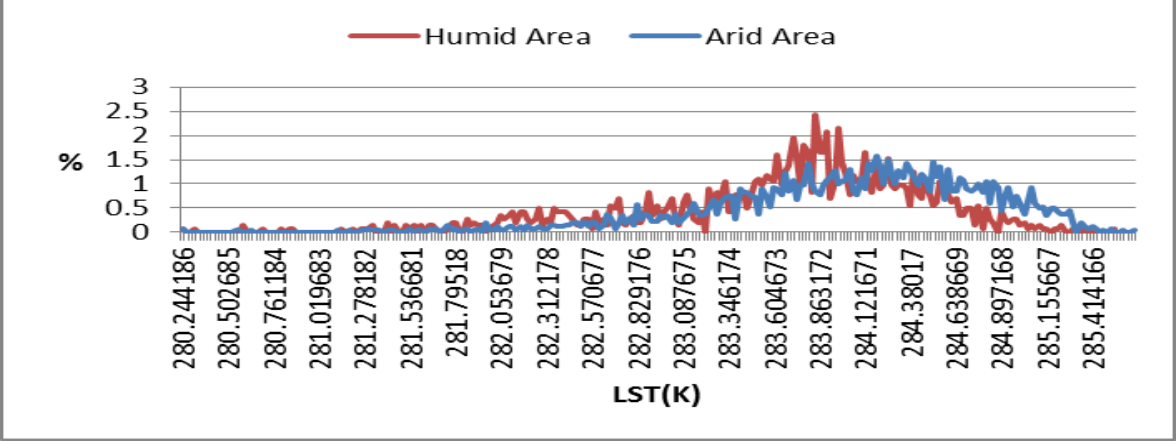

Figure 9 The Cumulative probability distribution of surface temperature in arid and humid areas

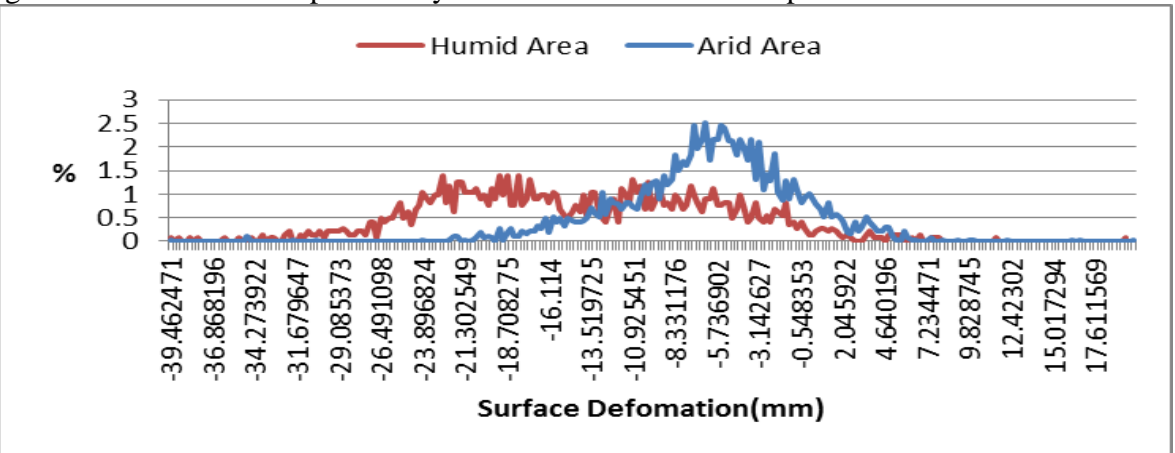

Figure 10 The Cumulative probability distribution of surface deformation in dry and wet area

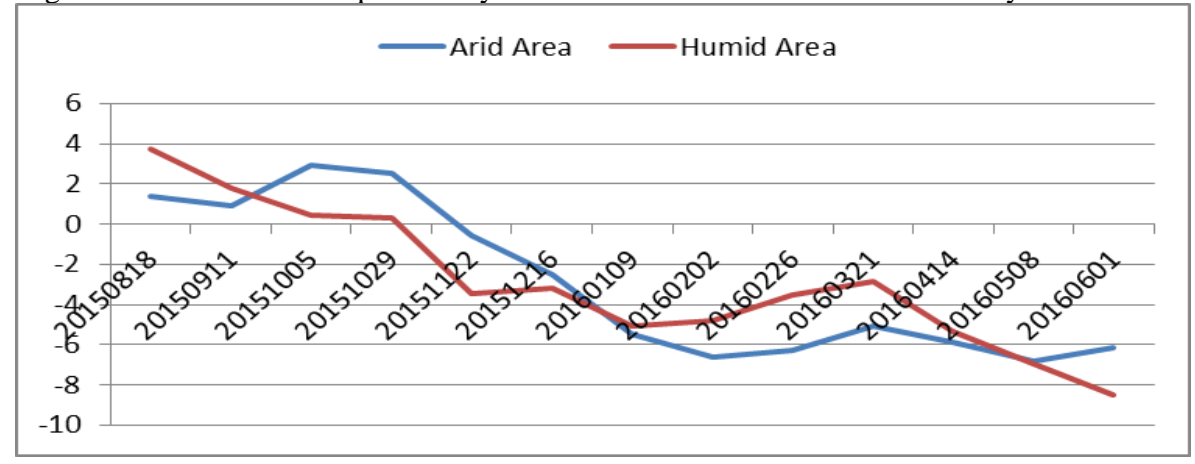

Figure 11 The Maximum distribution probability of surface deformation in dry and wet area 